\title{
Notas marginales sobre la culpa contractual, como elemento del derecho de opción del acreedor
}

\author{
Marginal notes on the contractual guilt, as an element of the \\ creditor's right of option
}

\begin{abstract}
RESUMEN
La presente investigación tiene por finalidad analizar la culpa o negligencia, particularmente como requisito del derecho de opción del acreedor, ante el incumplimiento contractual. Analizaré el tema, principalmente, a la luz de la doctrina y jurisprudencia españolas.
\end{abstract}

\section{PALABRAS CLAVE}

Responsabilidad contractual, Culpa, Derechos del acreedor, Incumplimiento contractual, Derecho de remedios.

\begin{abstract}
The following research is intended to analyze the fault or negligence, particularly as a requirement of the creditor's right of option, in the event of a contract breach. I will analyze the subject, mainly, in the light of the Spanish doctrine and jurisprudence.
\end{abstract}

\section{KEYWORDS}

Contractual responsibility, Fault, Creditor's rights, Breach of contract, Right of solutions.

\section{JOSÉ MAXIMILIANO RIVERA RESTREPO}

Facultad de Filosofía y Humanidades de la Universidad de Chile. Abogado de la Universidad de Chile y Magíster en Derecho, con mención en Derecho Privado por la Universidad de Chile. Máster Universitario en Derecho Privado por la Universidad Complutense de Madrid. Doctor en Derecho Civil por la Universidad Complutense de Madrid. Notario Público, Conservador de Bienes Raíces, de Comercio, Minas y Archivero Judicial Suplente de Tocopilla. Profesor de Jornada de Derecho Civil en la Universidad Gabriela Mistral. Diplomado en Docencia Universitaria, Universidad Gabriela Mistral. Dirección postal: Ricardo Lyon N 1177, Providencia, Santiago de Chile, Código Postal: 7510549. jose.rivera@ugm.cl

Este artículo forma parte de una investigación mayor, que dará lugar a la publicación de un libro sobre la materia. 
"El resultado del encuentro rirme, aunque sea tangencialmente, a ellos*. era la lei suprema de la razón". La doctrina ha señalado que el deudor debe (Tomás Guevara, 1904, p.41) actuar con prudencia, de tal manera que es responsable. Se dice que el elemento intencional, propio del dolo, no está presente en la culpa**, sin que esté del todo ausente el elemento voluntario del agente"

En España, mucho se ha discutido acerca de elemento subjetivo (culpa o dolo), como requisito para que opere el derecho de opción del acreedor. La doctrina española moderna prescinde de cualquiera consideración subjetiva, a la hora de analizar la posible aplicación del derecho de opción del acreedor ante el incumplimiento contractual. En este punto, cabe preguntarse ces posible asimilar la existencia de un caso fortuito o fuerza mayor a una conducta negligente o dolosa de parte de uno de los contratantes, a la hora calificar el incumplimiento? Pues bien, interesa analizar algunos aspectos de relevancia a propósito de la culpa o negligencia, no solo por consideraciones éticas o morales, sino que, además, para mantener viva la polémica en cuanto a su exigencia, como presupuesto de aplicación del derecho de opción del acreedo

\section{Generalidades}

Si bien no pretendo elaborar en este ensayo, una dogmática acerca de la culpa contractual*; existen algunos puntos relevantes a los que pretendo referirme. La culpa, como requisito del derecho de opción, debo refe-

Cfr. Medicus (1995), p.59. Aunque para la culpa preconSerramalera (1982), p.55.
En general, se entiende por culpa la falta de la debida diligencia o cuidado en el cumplimiento de una obligación o en la ejecución de un hecho":. El CC español, en su artículo 1104 dispone que: "La culpa o negligencia de deudor consiste en la omisión de aquella diligencia que exija la naturaleza de la obligación $y$ corresponda a las circunstancias de las personas, del tiempo y del lugar" . La culpa denota siempre la idea de un descuido^ o

(2007), pp.164 SS.
*n este sentido, De Ruggiero (1977) señala que: “Cuando aquel elemento de la intención manifiesta que es
característico del comportamiento doloso falta en acto humano productor del daño en que esté ausente elemento voluntario en el agente, se tiene la culpa; esta presupone la voluntariedad del acto, del que deriva el agente por no haber sabido prever y evitar los efectos

.- Al pespecto, vid. Compagnucici de Caso (1997), p.129,
Cristobal Montés (1989), p.100; De la Peza Muñoz Cano (2009), p.142; Acedo Penco (2011), p.173.

En este sentido, Pasquau Liaño; Albiez Dohrmann y Lopez Frias (2000) señalan que: “El art. $1.104 \mathrm{CC}$, a diferen-
cia de lo que sucede en Derecho Comparad, donde códigos dan por sabido el concepto, brinda -o impon según se mire-, una determinada noción de culpa [....

- Para Albaladejo García (2011): "En sentido amplio hay
culpa del deudor cuando el quebrantamiento de la oblinegligensteientementente, no se quiere cumplir o poraus de forma irreparable, por el vencimiento de una obligación que no recordaba)" (p.175).

- En este sentido, O'Callaghan Muñoz (2008), siguiendo a
Larenz, señala que: "Obra culposamente el que descuida dañosos del acto" (p.125). gación le es imputable (por ejemplo, no se cumple porla diligencia exigida en el trá́ico" ( $(p .171)$ falta de preocupación de una persona*. Este descuido puede incidir en el incumplimiento de una obligación que ya existía, o en la ejecución de un hecho determinado**. Desde este punto de vista, Espín Cánovas define a la culpa o negligencia contractual como "[...] el incumplimiento de la obligación ocasionado por la falta de diligencia del deudor, pero sin intención deliberada de incumplir (Espín Cánovas, 1983, p.119). Por su parte, la STS de 20 de junio de 1994, señala que la culpa "[...] no consiste en la omisión de normas inexcusables, sino en el actuar no ajustado a la diligencia exigible, según las circunstancias del caso concreto, de las personas, tiempo y lugar, para evitar perjuicios a bienes ajenos, lo que sitúa la diligencia exigible en la que correspondería al buen padre de familia"

En materia de responsabilidad civil, hay que

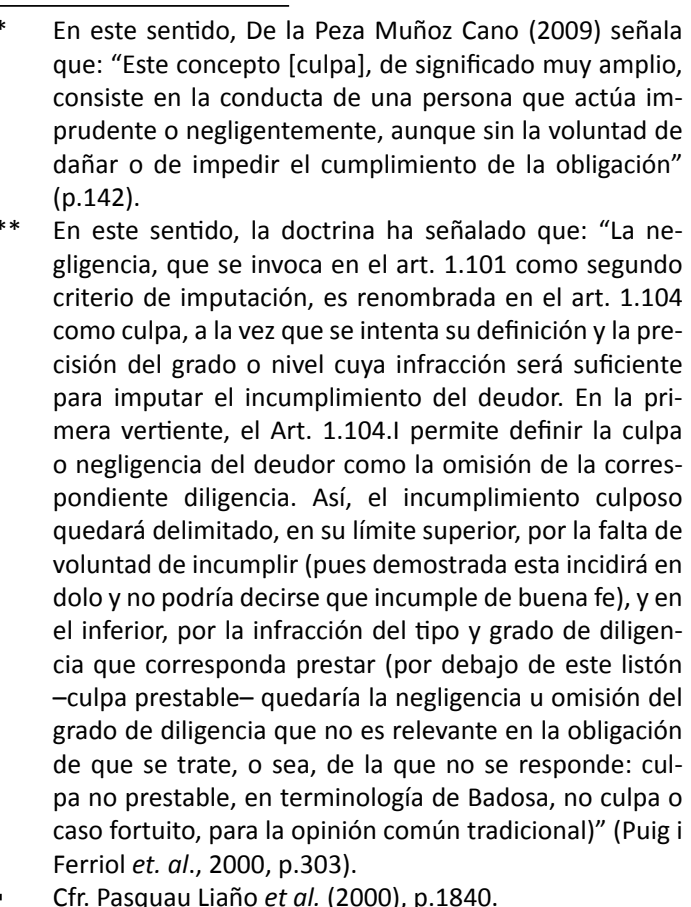

En este sentido, De la Peza Muñoz Cano (2009) señala
que: "Este concepto [culpal de significado muy amplio,

alado que: "La neombrada en el art. 1.104

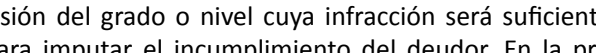
mera vertiente, el Art 1 iresto del deudor. En la priostrada esta incidirí en el tipo y grado de diligenonde: cul (Pvi

Cfr. Pasquau Liaño et al. (2000), p.1840. distinguir entre la responsabilidad contractual* y extracontractual**. No es del caso entrar al tratamiento pormenorizado de una y otra", y basta, para el análisis de este trabajo, considerar un concepto de culpa en general y la determinación de la misma en materia contractual"'. En opinión de la doctrina, la culpa"

En Italia, Trimarchi (1996) señala que: "In larghi settori
della materia contrattuale la responsabilità è fondata sulla colpa. Ciò vale innanzi tutto per le obbligazioni che hanno per oggetto un fare, come resulta da una serie di gli obblighi del mandatario, dell'appaltatore, del vettore (art. 1710, 1668,1681 cod. Civ.) e, ancora, a propósito degli obblighi del lavatore subordinato e del profesio-
nista, dove lo stesso contenuto della prestazion è definitito in base al criterio della diligenzza (art. 2104, 1176,2236 cod. Civ..). Ė chiaro che, nell'ambito di questo tipo di obblighi, il principio ha validità generale, anche
fuori dalle ipotesi specificamente considere dalla legge"

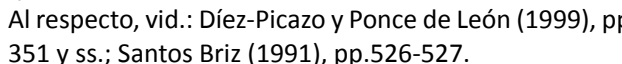
En este sentido, Pasquau Liaños, Albiez Dohrmann y Ló-

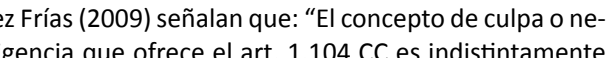
aplicable a los supuestos de responsabilidad contractual extracontractual" (p.1885).

Además, desde el punto de vista del modo, la culpa se positivo, cuando el agente ejecuta una conducta que no debía realizar, y culpa in non faciendo, cuando el agente incurre en una omision, cuando estaba obligado por .

(2003) señalan que: "A poco que se examine la docctrina sobre la culpa puede claramente observarse que, a grandes rasgos, se distingue una posición clásica, invariablesable la omisión de la diligencia exigible al agente, y una posición moderna, que caracteriza la culpa por notas distintas que esa falta de diligencia, y que llega a hablar do clásico de la culpa civil parte de identificicarla con neligencia, concepto que se contrapone al de diligencia. Está basada en la culpabilidad, dominada por el criterio subjetivo. En definitiva, es una conducta voluntaria condel hecho propio. No prestar la diligencia que se debe prestar, ocasionando con ello el incumplimiento de una obligación" (p.405). 
se diferencia claramente del dolo*, por cuan- En cuanto a la forma de apreciar la culpa, to, este conlleva la noción de la conciencia el Code francés, establece que el juez debe de perjudicar a otro**; en cambio, en aquella, apreciar la culpa conforme al módulo de no existe esta conciencia o conocimiento". buen padre de familia* (artículo 1137 de Albadejo García (2011) señala que: "Hay cul- Code), es decir, el modelo francés equivale a pa en sentido estricto cuando, sin intención deliberada de transgredir la obligación, el to**. Por su parte, el Código Civil alemán deudor infringe esta por falta de diligencia" dispone que: "Obra culposamente quie (p.177)"*.

La culpa está integrada por dos elementos: uno subjetivo y otro objetivo ${ }^{\star}$. El primero se refiere a la negligencia o falta de cuidado, sin llegar a constituir una intención de incumplir (dolo); el segundo, se refiere a la imposibilidad definitiva del cumplimiento de la prestación. Este último elemento, diferencia a la culpa de la mora y del simple retraso en el cumplimiento de la obligación « . Para O'Callaghan (2012): “El concepto de culpa se forma con un elemento positivo y otro negativo: este consiste en que no tenga intención de incumpliry aquel es la negligencia" (p.171).

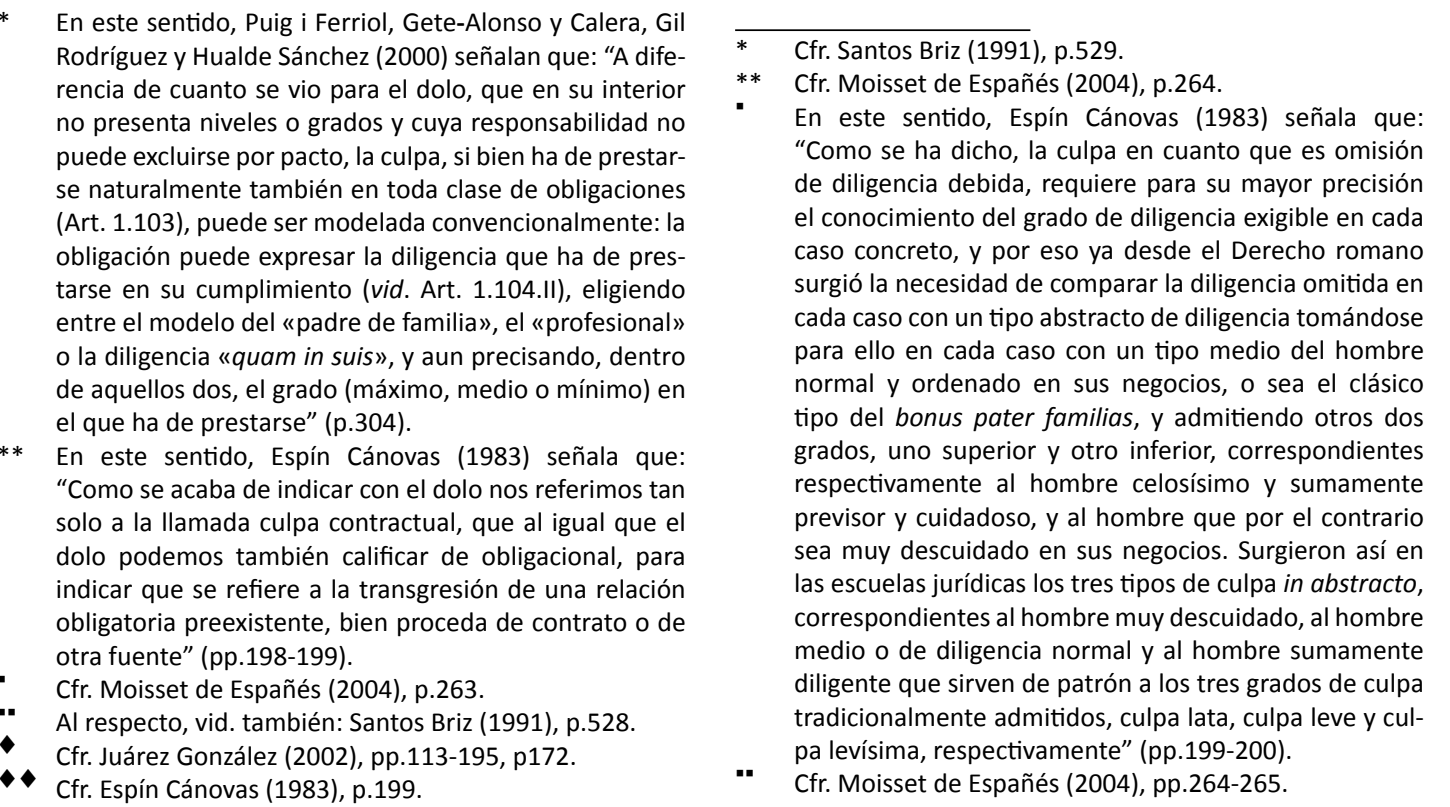

En este sentido, Puig i Ferriol, Gete-Alonso y Calera,
Rodriguen y Hualde Sánchez (2000) señalan que: "A dife作 resar la diligencia que ha de (a) que ha de prestarse" (p. 304). nn este sentido, Espin Cánovas (1983) señala que:
"Como se acaba de indicar con el dolo nos referimos to solo a la llamada culpa contractual, que al igual que

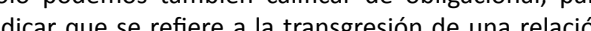
Cfr. Moisset de Españés (2004), p.2.263. deudor*, con el comportamiento que el Derecho le exige al mismo, conforme a la teoría de los grados**.

\section{Una nota sobre la culpa contractua}

Frente a la teoría clásica, heredada del Derecho romano, conforme a la cual, la culpa contractual se gradúa", se presenta una teoría moderna, según la cual se plantea la libre apreciación de la culpa". Con todo, la Ley de 3 de mayo de 1981, que reforma el CC, introdujo la asimilación de los efectos del dolo y la culpa grave o lata en algunos casos (arts. 168, apartado 20 y 1366 ). El artículo 168 apartado 20 del CC dispone que: "En caso de pérdida o deterioro de los bienes por dolo o culpa grave, responderán los padres de los daños y perjuicios sufridos". Por su parte, e art. 1366 CC español señala lo siguiente: “Las obligaciones extracontractuales de un cónyuge, consecuencia de su actuación en bene-

En este sentido, Pasquau Liaño, Albiez Dohrmann López Frias (2000) señalan que: "El modelo concreto de diligencia que establece el parrafo primero del art. la jurisprudencia, que viene señalando cómo la conducta diligente no exige solo adecuarse a la naturaleza $\mathrm{de}$ la obligación, según las circunstancias de las personas . nuncian las SSTS 16 junio 1967 [R. 3487], 5 marzo 1982 [R. 1286]. 27 mayo 1982 [R. 2603], 22 marzo 1983 [R. 1573], 27 mayo 1983 [R. 2916], 25 enero 1985 [R. 199], mayo 1986 (R. 20. (1999) señalan que: "Dentro de la culpa, la doctrina tra(1)

Este inconveniente también se presenta en el sistema
juridico mexicano, que, al igual que el español, no tiene normas claras que fijen el sistema aplicable para la apre-

p.143.
Cfr. Die-

Cr. Diez-Picazo y Ponce de León y Gullón (2005), p.200. ficio de la sociedad conyugal o en el ámbito de la administración de los bienes, serán de la responsabilidad y cargo de aquella, salvo si fuesen debidas a dolo o culpa grave del cónyuge deudor"*. Para Albaladejo García, la culpa contractual admite una graduación**.

El CC español, dispone en el artículo 1104 apartado 2o lo siguiente: "Cuando la obligación no exprese la diligencia que ha de prestarse en su cumplimiento, se exigirá la que correspondería a un buen padre de familia"". Esta norma se erige como el prototipo de diligencia normal que se le exige a una persona (culpa leve in abstracto)"', a partir de la cual se mide la negligencia del deudor en los diversos supuestos que se presenten ${ }^{\star}$. Esta es la opinión mayoritaria de la doctrina, porque, según algunos en el sistema español se consagra el sistema de libre apreciación de la culpa (Castán, Puig Peña). Se basan en lo dispuesto en el artículo 1103, que señala: "La responsabilidad que proceda de negligencia es igualmente exigible en el cumplimiento de toda clase de obligaciones; pero podrá moderarse por los tribunales según los ca-

Al respecto, vid.: Santos Briz (1991), p.640.
$* *$ Cfr. Albaladejo García (2011), p.179. Ctr. O'Callaghan Muñoz (2006), p.1087., Pasquau Liaño et al. (2009), pp.1885 y ss. a objetivo de apreciación de la culpa. Cfr. Santos Briz (1991), p.529.

(1983) p.200

En este sentido, para la jurisprudencia, con el fin de
apreciar la culpabilidad ".... no solo ha de atenderse a la diligencia exigible según las circunstancias de personas, vida social en que la conducta se proyecte $y$ determinar si el agente obró con el cuidado, atención o perseverancia exigibles y con la reflexion necesaria, con vistas a gidos (S 22 marzo 1983)" (Albácar López \& Santos Briz, 1991, p.87). 
"El Código Civil no sigue la antigua distinción de grados de culpa y este artículo 1.103 tampoco es una consecuencia de dicha distinción" (p.1080).

Estos dos sistemas podrían coexistir en el CC porque si bien autoriza al juez para apreciar la culpa según las circunstancias de las personas, del tiempo y del lugar y de atenuar su responsabilidad por culpa según los casos, por otra parte, dispone que la obligación que no expresa la diligencia que ha de prestarse en su cumplimiento, quedará bajo la influencia de la culpa leve*.

No es del caso analizar en detalle la culpa, sino que, por el contrario, en este acápite nos interesa dejar claro que ella constituye un elemento necesario para que opere el derecho de opción. Aun cuando mi opinión navegue en contra de la corriente, creo que ella se ajusta a Derecho, por cuanto está conforme con los principios de buena fe y equidad natural.

\section{III. ¿Es necesaria la culpa para que opere el} derecho de opción del acreedor?

Por influencia del common law, se ha tendido a objetivizar los elementos necesarios para que opere el derecho de opción de acreedor, así, ya no se incluye la exigencia de imputabilidad para que uno de los contratantes sea calificado de incumplidor. Ello, creo

Cfr. Espin Cánovas (1983), pp.200-201. En Alemania, En-
neccerus señala que: "La responsabilidad por negligencia leve es la regla en el Código Civil, con mayor precisión que en el Derecho Común". Cfr. Enneccerus (1954),

EVVITA VIS IURIS I No. 3, VVol 2 | 9 - 17 | Enero-Junio, 2015 I Universidad Sergio Arboleda I Escuela de Derecho I Seccional Santa Marta, Sede Centro que es errado, por cuanto el Derecho ha de estructurarse sobre la base de antecedentes conductuales morales. Eliminar la exigencia de culpa, sería igualar, en la práctica, la conducta culpable al caso fortuito o fuerza mayor, prescindiendo del juicio de reproche a la persona del contratante incumplidor. Como indico en otro artículo: "No es posible que se le atribuyan las mismas consecuencias al contratante inocente, que al culpable. Dich inocencia justifica que el deudor quede liberado de sus obligaciones. Es muy importante que se den claramente los elementos que conforman el caso fortuito o fuerza mayor" (Rivera Restrepo, año, p.)

Así las cosas, renunciar a esta exigencia re sulta inconcebible, aunque estos elementos "metajurídicos" alteren en plan de unificación y armonización del Derecho europeo de las obligaciones y contratos, toda vez que ellos se sustentan en principios de carácter etico, los que le dan coherencia y armonía a Derecho.

\section{De la prueba de la culpa*}

El primitivo artículo 1214 del CC españo derogado por la Ley $1 / 2000$, de 7 de enero, de Enjuiciamiento Civil, BOE núm. 7, de 8-1-2000), disponía que: "Incumbe la prueba de las obligaciones al que reclama su cumplimiento, y la de su extinción al que la opone". Por su parte, el artículo 1183 del CC español dispone que: "Siempre que la cosa se hubiese perdido en poder del deudor, se presumirá que la pérdida ocurrió por su cul- pa y no por caso fortuito, salvo prueba en contrario, y sin perjuicio de lo dispuesto en el artículo 1096"*. Por lo tanto, corresponderá al deudor acreditar que la extinción del vínculo obligacional no se debió a su culpa o negligencia**. Dicho de otra forma, la culpa contractual se presume". El CC, frente a un incumplimiento por parte del deudor, presume que ese incumplimiento ha sido culpable. En este sentido lo ha entendido la jurisprudencia (STS de 20 de septiembre de 2004)". En efecto, si el deudor sostiene que el incumplimiento se ha debido a la existencia de un caso fortuito deberá acreditarlo; por su parte, si el acreedor señala que la conducta del deudor fue dolosa, en este caso deberá probar la existencia de dolo. A diferencia de dolo, la culpa goza de una cierta benignidad que se traduce no solamente en que esta podrá ser moderada por el juez ${ }^{\star}$, sino que

Fneste sentide, O'Callaghan Muñoz (2008) seña que: "Cuando se produce el incumplimiento de una obligación se presume que lo ha sido por culpa del deudor. este incumple totalmente o cumple defectuosamente, na se supone que es voluntaria $y$ si el incumplimientoha sido por caso fortuito o fuerza mayor, deberá proado el deudor [sicl, son hechos impeditivos de su resCr. Albal (1983), p.202. En este sentido, Dízz-Picazo y Ponce de León y Gullón nante, basada en que el incumplimiento es imputable a deudor que incurre en culpa o negligencia, estima que al acreedor le basta la alsacionn del incumplimiento $d e$ culpa del deudor por aplicación analógica del artículo 1.183 , y en consecuencia, sobre él recae la carga de pro-

- bar las causas por la que no le es imputable (p.20). artículo 1183 [del Código Civill, que establece la presunción de culpa del deudor como causa de la pérdida de la cosa que estaba en su poder, salvo prueba de la conprincipio se recoge en los artículos 307 y 361 del Código de Comercio, asi como en el artículo 1302 del Código

Cfr. O'Callaghan Muñoz (2008) pp 172-173, Pasqua Cfr. O'Callaghan Muñoz (2008), pp.172-173; Pasquaa
Liaño et al. (2009), p.1884; Santos Briz (1991), p.528. también por la extensión de los perjuicios que deberán ser indemnizados por el deudor. Sobre este último punto, el artículo 1107 del CC dispone que: "Los daños y perjuicios de que responde el deudor de buena fe son los previstos o que se hayan podido prever al tiempo de constituirse la obligación y que sean consecuencia necesaria de su falta de cumplimiento. En caso de dolo responderá el deudor de todos los que conocidamente se deriven de la falta de cumplimiento de la obligación"**

\section{CONCLUSIÓN}

En aras de la equidad natural y del principio de la buena fe, estimo relevante considerar al elemento subjetivo (culpa o dolo), como elemento integrante del derecho de opción del acreedor, ante el incumplimiento contractual. Me pregunto ¿es lo mismo incumplir una obligación por caso fortuito o fuerza mayor que por existir una conducta reprochable al contratante incumplidor, por existir de su parte negligencia o malicia? Pareciera que no, pues, el Derecho tiene la misión de reprimir las conductas que escapan a la normalidad de los hechos y se esgrimen como circunstancias insólitas y anormales.

De lo anterior se deriva, que quien pretenda esgrimir la existencia de una conducta culpable o dolosa de parte del otro contrayente, deberá acreditarla.

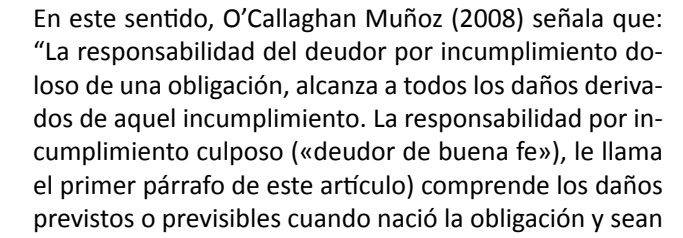
pevistos o previsibles cuando nació la obligación y y sean consecuencia necesaria del incumplimiento" (p.1093). 


\section{ÍNDICE DE SENTENCIAS}

STS de 8 mayo de 1986, (RJ/1986/2669).

STS de 25 enero de 1985, (RJ/1985/199).

STS de 27 mayo de 1983, (RJ/1983/2916).

STS de 22 marzo de 1983, (RJ/1983/1573).

STS de 27 mayo de 1982, (RJ/1982/2603).

STS de 5 marzo de 1982, (RJ/1982/1286).

STS de 16 junio de 1967, (RJ/1967/3487).

\section{REFERENCIAS}

Acedo Penco, Á. (2011). Teoría general de las obligaciones. $2^{\mathrm{a}}$ edición revisada. Madrid: Editorial Dykinson, S. L.

Albácar López, J. L. \& Santos Briz, J. (1991). Libro IV. De las obligaciones. Títulos I y II. En Código Civil. Doctrina y jurisprudencia IV. (Doctrina, antecedentes y concordancias de Jaime Santos Briz y José Ángel Torres Lana, José Luis Albácar López, Direct., coord., selección de la jurisprudencia, índices y bibliografía (pp.3-843). Madrid: Editorial Trivium S.A.

Albaladejo García, M. (2011). Derecho Civil. II. Derecho de Obligaciones. Decimocuarta edición. Madrid: Edisofer, S.L.

Compagnucci de Caso, R. H. (1997). Manual de obligaciones. Buenos Aires: Editorial Astrea de Alfredo y Ricardo Depalma.

Cristóbal Montés, Á. (1989). El incumplimien to de las obligaciones. Madrid: Editorial Tecnos, S.A.
De la Peza Muñoz Cano, J. L. (2009). De las obligaciones. Quinta edición. México: Editorial Porrúa.

De Ruggiero, R. (1977). Instituciones de Derecho Civil II, vol. primero. Trad. de la $4^{a}$ edición italiana, anotada y concordada con la legislación española por Ramón Serrano Suñer y José Santa-Cruz Tejeiro. Madrid: Instituto Ed. Reus.

Díez-Picazo \& Ponce de León, L. (1999). Derecho de daños. Madrid: Civitas.

Díez-Picazo, Ponce de León L \& Gullón, A. (2005). Sistema de Derecho Civil II. Noven edición, $5^{a}$ reimpresión. Madrid: Editorial Tecnos S.A.

Enneccerus, L. (1954). Derecho de obligaciones. Undécima revisión por Henrich Lehmann, trad. de la $35^{a}$ edición alemana, Estudios de comparación y adaptación a la legislación y jurisprudencia españolas por Blas Pérez González y José Alguer, vol. Primero, Doctrina general. Segunda edición al cuidado de José Puig Brutau. Bosch, Barcelona: Casa Editorial.

Espín Cánovas, D. (1983). Manual de Dere cho Civil español III. Sexta edición revisada ampliada conforme a la Constitución y leyes de reforma del Código Civil. Madrid: Editorial Revista de Derecho Privado.

Guevara, T. (1904). Costumbres Judiciales. Enseñanza de los araucanos. Santiago Chile: Imprenta Cervantes.
Juárez González, J. M. (2002). Cumplimiento, incumplimiento y extinción de las obligaciones. Parte primera. Cumplimiento, incumplimiento de las obligaciones. En Vicente L. Simó Santonja (Coord.), Instituciones de Derecho Privado III. (pp.113-195). Madrid: Civitas Ediciones, S. L.

Lacruz Berdejo, J. L., Sancho Rebullida, F. de A., Luna Serrano, A., Delgado Echeverría, Rivero Hernández, F. \& Rams Albesa, J. (2007). Elementos de Derecho Civil. II. Derecho de obligaciones I. $4^{\mathrm{a}}$ edición revisada y puesta al día por Francisco Rivero Hernández. Madrid: Dykinson.

Medicus, D. (1995). Tratado de las relaciones obligacionales I. Barcelona, Bosch: Casa Editorial, S.A.

Moisset de Españés, L. (2004). Curso de obligaciones 2. Buenos Aires: Zabalía, S.A.

O'Callaghan Muñoz, X. (2001). Código Civil. Comentado y con jurisprudencia. $2^{\mathrm{a}}$ edición Madrid: Editorial La Ley-Actualidad.

O'Callaghan Muñoz, X. (2006). Código Civil. Comentado y con jurisprudencia. $5^{a}$ edición. Madrid: Editorial La Ley.

O'Callaghan Muñoz, X. (2008). Compendio de Derecho Civil II. $5^{\text {a }}$ edición, corregida y puesta al día. Madrid: Ediciones Jurídicas DIJUSA, S.L.

O'Callaghan Muñoz, X. (2012). Compendio de Derecho Civil II. Madrid: Editorial Centro de Estudios Ramón Areces, S.A.
Pasquau Liaño, M. (Direct.), Albiez Dohrmann, K. J. \& López Frías, A. (Coords.) (2009). Jurisprudencia Civil Comentada. Código Civil I. $2^{\mathrm{a}}$ edición. Granada: Editorial Comares,

Pasquau Liaño, M. (2000). Jurisprudencia Civil Comentada. Código Civil II. Granada: Editorial Comares, S.L.

Puig i Ferriol, LL., Gete-Alonso y Calera, Maㅗ del C., Gil Rodríguez, J. \& Hualde Sánchez, J. J. (2000). Manual de Derecho Civil II. 3a edición. Barcelona: Marcial Pons, Ediciones Jurídicas y Sociales, S.A.

Rivera Restrepo, J. M. “Es necesaria la imputabilidad para que opere el derecho de opción del acreedor?, artículo aceptado por la Revista Boliviana de Derecho y Actualidad Jurídica, de la Facultad de Derecho de la Universidad de Valencia (España).

Ruiz Serramalera, R. (1982). Derecho Civil. Derecho de Obligaciones II. Los contratos y los actos ilícitos. Madrid: Universidad Complutense de Madrid, Facultad de Derecho, Secc. de Publicaciones.

Santos Briz, J. (1991). Código Civil (comentarios y jurisprudencia). Granada: Editorial Comares.

Santos Briz, J. (Direct.) \& Sierra Gil de la Cuesta, I. (2003). Tratado de Derecho Civil. Teoría y práctica. Derecho de obligaciones 3. Barceona: Editorial Bosch S.A.

Trimarchi, P. (1996). Istituzioni di Diritto privato. Undicesima edizione. Milano: Dott. A. Giuffrè Editore, S. p. A. 